OAK RIDGE

NATIONAL LABORATORY

MANAGED BY UT-BATTELLE

FOR THE DEPARTMENT OF ENERGY

\title{
Hardness of Carburized Surfaces in 316LN Stainless Steel after Low Temperature Neutron Irradiation
}

January 2005

T. S. Byun and K. Farrell

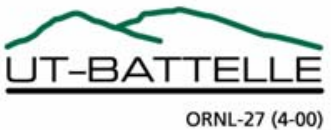


This report was prepared as an account of work sponsored by an agency of the United States government. Neither the United States government nor any agency thereof, nor any of their employees, makes any warranty, express or implied, or assumes any legal liability or responsibility for the accuracy, completeness, or usefulness of any information, apparatus, product, or process disclosed, or represents that its use would not infringe privately owned rights. Reference herein to any specific commercial product, process, or service by trade name, trademark, manufacturer, or otherwise, does not necessarily constitute or imply its endorsement, recommendation, or favoring by the United States government or any agency thereof. The views and opinions of authors expressed herein do not necessarily state or reflect those of the United States government or any agency thereof. 
Metals and Ceramics Division

\title{
HARDNESS OF CARBURIZED SURFACES IN 316LN STAINLESS STEEL AFTER LOW TEMPERATURE NEUTRON IRRADIATION
}

\author{
T. S. Byun and K. Farrell
}

Date Published: January 2005

Prepared by

OAK RIDGE NATIONAL LABORATORY

Oak Ridge, Tennessee 37831-6285

managed by

UT-BATTELLE, LLC

for the

U.S. DEPARTMENT OF ENERGY

under contract DE-AC05-00OR22725 



\section{CONTENTS}

Page

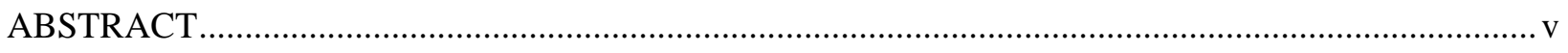

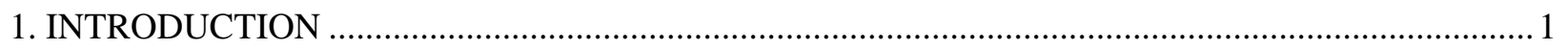

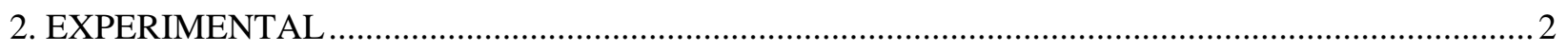

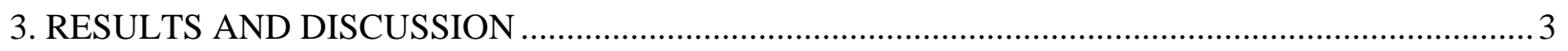

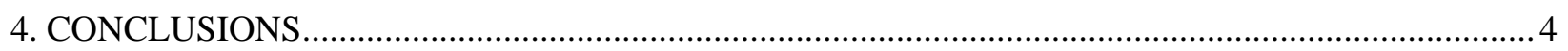

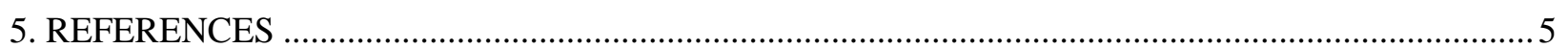





\begin{abstract}
A proprietary surface carburization treatment is being considered to minimize possible cavitation pitting of the inner surfaces of the stainless steel target vessel of the SNS. The treatment gives a large supersaturation of carbon in the surface layers and causes substantial hardening of the surface. To answer the question of whether such a hardened layer will remain hard and stable during neutron irradiation, specimens of the candidate materials were irradiated in the High Flux Isotope Reactor (HFIR) to an atomic displacement level of $1 \mathrm{dpa}$. Considerable radiation hardening occurred in annealed 316LN stainless steel and 20\% cold rolled 316LN stainless steel, and lesser radiation hardening in Kolsterised layers on these materials. These observations coupled with optical microscopy examinations indicate that the carbon-supersaturated layers did not suffer radiation-induced decomposition and softening.
\end{abstract}





\section{INTRODUCTION}

In the Spallation Neutron Source (SNS), a 316LN austenitic stainless steel vessel will be used to hold the flowing liquid mercury target [1,2]. Although 316LN steel is known to have excellent resistance to general corrosion and to retain excellent ductility after irradiation, the interior surface of the vessel could be subjected to pitting erosion due to collapse of cavities created in the mercury by the pulsed proton beam [1]. This type of cavitation pitting is common in hydraulic systems where perturbed flow is encountered [3,4], and it generally can be diminished by increasing the hardness (strength) of the vessel [5]. Several techniques have been considered to mitigate concerns about pitting erosion in the SNS target vessel. One technique that has shown good promise is a commercial surface hardening treatment known as Kolsterising ${ }^{\circledR}[3]$.

Kolsterising $^{\circledR}$ is the registered trade name of a proprietary surface carburization treatment for austenitic alloys provided by Bodycote Kolsterising ${ }^{\circledR}$ North America, Boaz, Alabama. Kolsterising ${ }^{\circledR}$ is a process in which carbon is diffused into the surface of an austenitic alloy at low temperature. Bodycote's regular treatment purportedly affects a layer about $33 \mu \mathrm{m}$ deep. Within the layer, the infiltrated carbon is claimed to be incorporated in supersaturated interstitial solid solution in the austenite phase of the steel. Special advantages are said to be improved resistance to pitting, stress corrosion, and crevice corrosion; increased resistance to wear and galling; and greater fatigue properties [3].

To verify these promotional claims and to uncover any factors that might be of concern for the integrity of a Kolsterised target vessel, the surface layers of Kolsterised austenitic 316LN stainless steel have been characterized at ORNL [4,5]. The carburized layer was about $35 \mu \mathrm{m}$ thick with some variations. Its indentation hardness (by 50-g load) at the surface was about $1040 \mathrm{HV}_{0.05}$, five times larger than that of the substrate steel, $\sim 200 \mathrm{HV}_{0.05}$, and declined rapidly with depth into the layer following the carbon concentration gradient. The corrosion resistance of the carburized layer in an acid medium was greater than that for untreated austenite. Even with the high hardness, the layer was plastically deformable and was quite resistant to cracking during straining. The maximum carbon content of the layer was much less than the claimed 6-7 wt\% carbon, and the carbon was not simply contained in supersaturated solid solution; some of it was present in a previously unreported iron carbide phase located at the very surface. Inclusion stringers and ferrite phase embraced in the treated layer were less resistant to chemical attack than the treated austenite.

Although the above findings support most of the advertised claims for the Kolsterized layer, those did not include radiation effects. Irradiation usually hardens a material; however, it can soften a material that has previously been hardened by other mechanisms. In particular, irradiation can cause decomposition of metastable solid solutions [6,7]. Such decomposition might reduce the hardness and pitting resistance of a Kolsterised surface layer. To determine whether radiation-induced softening is likely to occur in the SNS target vessel during operation, the hardness of a Kolsterised layer has been measured after neutron irradiation. The results are reported herein. 


\section{EXPERIMENTAL}

Disk samples intended for transmission electron microscopy (TEM) studies, and slivers cut from TEM disks in a variety of material conditions, were irradiated in the Hydraulic Tube facility of the HFIR to a neutron fluence of $1.2 \times 10^{25} \mathrm{n} \cdot \mathrm{m}^{-2}(\mathrm{E}>0.1 \mathrm{MeV}$ ), corresponding to an atomic displacement dose of $\sim 1 \mathrm{dpa}$, at a temperature of $60-100^{\circ} \mathrm{C}$ in direct contact with flowing water coolant. The 316LN stainless steel specimens were irradiated in 6 different conditions: as-annealed, annealed-and-Kolsterised, 20\% (or $74 \%$ ) cold- rolled (CR), and $20 \%$ (or 74\%) CR-and-Kolsterised conditions. The Kolsterising ${ }^{\circledR}$ treatments were conducted by Bodycote to a $33 \mu \mathrm{m}$ depth. Of these materials and conditions, the annealed and 20\% CR 316LN stainless steels are the most probable substrate choices for the SNS vessel. To date, only limited on-face microhardness testing and visual examination of the Kolsterised and non-Kolsterised surfaces have been performed on those selected materials.

Hardness tests were performed in an automatic micro-Vickers hardness testing system (Mitsutoyo AAV-500). Because the Kolsterised layer is only about $35 \mu \mathrm{m}$ thick, microhardness indentations made at a high load will penetrate through the hardened layer and give falsely low readings. Bodycote Group uses a load of $50 \mathrm{~g}$. We found that at $50 \mathrm{~g}$ the diagonal lengths of the pyramidal impressions in Kolsterised surfaces were about $10 \mu \mathrm{m}$, which is less than one third of the thickness of Kolsterised layer. Therefore, a hardness value measured at 50 -g load is believed to give a good representation of the strength of the hardened layers. Five or six hardness measurements were made for each specimen, and the dwell time at a constant load in each indentation test was 10 seconds. Optical microstructures were observed using the microscope of the hardness testing system, and the images were saved to electronic files. 


\section{RESULTS AND DISCUSSION}

The mean values of the on-face hardness values are presented in Fig. 1, along with the statistical bounds $( \pm 1 \sigma)$, and all measurements are listed in Tables 1 and 2 . The annealed material without Kolsterising ${ }^{\circledR}$ treatment showed the biggest increase in hardness by irradiation, an $81 \%$ increase from $162 \mathrm{HV}_{0.05}$ before irradiation. The hardness of the Kolsterised layer on the annealed material layer was about $939 \mathrm{HV}_{0.05}$ before irradiation, which is about 5.8 times higher than that of the as-annealed surface, and was increased by $11 \%$ to $1043 \mathrm{HV}_{0.05}$ after irradiation.

Because of the cold work in the $20 \%$ CR material, the hardness before irradiation was about $80 \%$ higher than the annealed material, and it increased about $43 \%$ to $418 \mathrm{HV}_{0.05}$ after irradiation.

Kolsterising ${ }^{\circledR}$ raised the surface hardness to $983 \mathrm{HV}_{0.05}$, not quite as hard as the layer on the annealed substrate. This small difference may be due to the expected presence of small quantities of strain-induced martensite phase in the $20 \% \mathrm{CR}$ material. According to Bodycote, non-austenitic phases are less responsive to Kolsterising ${ }^{\circledR}$ than is austenite. Irradiation increased the hardness value for the Kolsterised layer in the $20 \% \mathrm{CR}$ material very slightly to $1003 \mathrm{HV}_{0.05}$, which is within the experimental error bounds for the Kolsterised 20\%CR material before irradiation.

These hardness data indicate no signs of radiation-induced softening in the Kolsterised layers on both the annealed and 20\%CR substrate materials. On the contrary, irradiation actually increased the hardness of the annealed + Kolsterised condition.

The integrity of the Kolsterized layers after irradiation is also tentatively confirmed through microstructural observations. Figures 2 and 3 present typical microstructures and indentation impressions on the tested surfaces. Some rusting or surface contamination that occurred during irradiation or postirradiation storage, Figs. 2(b), 3(b), and 3(d) hampered the observations. Nevertheless, careful examinations revealed no convincing evidence of decomposition of the irradiated Kolsterised layers. The diagonal width of an indentation impression decreased from about $25 \mu \mathrm{m}$ in the as-annealed condition to about $9.5 \mu \mathrm{m}$ in the Kolsterised conditions. Slip bands were developed around the indentations. No cracking or flaking at impressions was observed, even on irradiated Kolsterised surfaces. In short, the Kolsterised layers do not seem to have been adversely affected by the neutron irradiation.

In the absence of detailed TEM studies of the microstructures of the irradiated Kolsterised layers, the present findings can not be taken as proof that the Kolsterised layers were fully resistant to irradiationinduced decomposition. But they do indicate that if some decomposition did occur it must have been on such a fine scale that it was not resolvable in the optical microscopy examinations and was not coarse enough to affect the hardness measurements, which would mean that the decomposition products would be no larger than about $1 \mu \mathrm{m}$. It is possible that radiation hardening of the Kolsterised layers might have offset the softening effects of any fine decomposition, resulting in a small net effect in microhardness. 


\section{CONCLUSIONS}

Neutron irradiation of SNS target vessel materials to an atomic displacement level of $1 \mathrm{dpa}$ produced considerable radiation hardening in annealed 316LN stainless steel and 20\% cold rolled 316LN stainless steel, and relatively minor hardening of Kolsterised (carburized) layers on these materials. These observations coupled with optical microscopy examinations indicate that the carbon-supersaturated surface layers did not suffer significant radiation-induced decomposition and softening. 


\section{REFERENCES}

1. L. K. Mansur, J. Nucl. Mater. 318 (2003) 14-25.

2. K. Farrell and T. S. Byun, Spallation Neutron Source Project Report, SNS/TSR-193, Oak Ridge National Laboratory, 2000.

3. “Kolsterising ${ }^{\circledR}$ ", a hard copy of a CD ROM dated August 2001, distributed by Bodycote Metal Technology; and some hard-copy fliers. Also, communications with Bodycote personnel.

4. K. Farrell, Results of Characterization Tests of the Surfaces of a Commercially Carburized Austenitic Stainless Steel, ORNL/TM-2003/115, Oak Ridge National Laboratory, 2003.

5. K. Farrell, E. D. Specht, J. Pang, L. R. Walker, A. Rar, and J. R. Mayotte, Characterization of a Carburized Surface Layer on an Austenitic Stainless Steel, presented at $6^{\text {th }}$ International Workshop on Spallation Materials Technology, Hayama, Kanagawa, Japan, December 2003. To be published in Journal of Nuclear Materials.

6. J. R. Holland, L. K. Mansur, and D. I. Potter, Editors, Phase Stability during Irradiation, Proceedings of A Symposium Sponsored by the Nuclear Metallurgy Committee at the Fall Meeting of the Metallurgical Society of AIME, Pittsburgh, Pennsylvania, October 5-9, 1980, The Metallurgical Society of AIME, Warrendale, PA, 1981.

7. K. C. Russell, J. Nucl. Mater. 206 (1993) 129-138. 


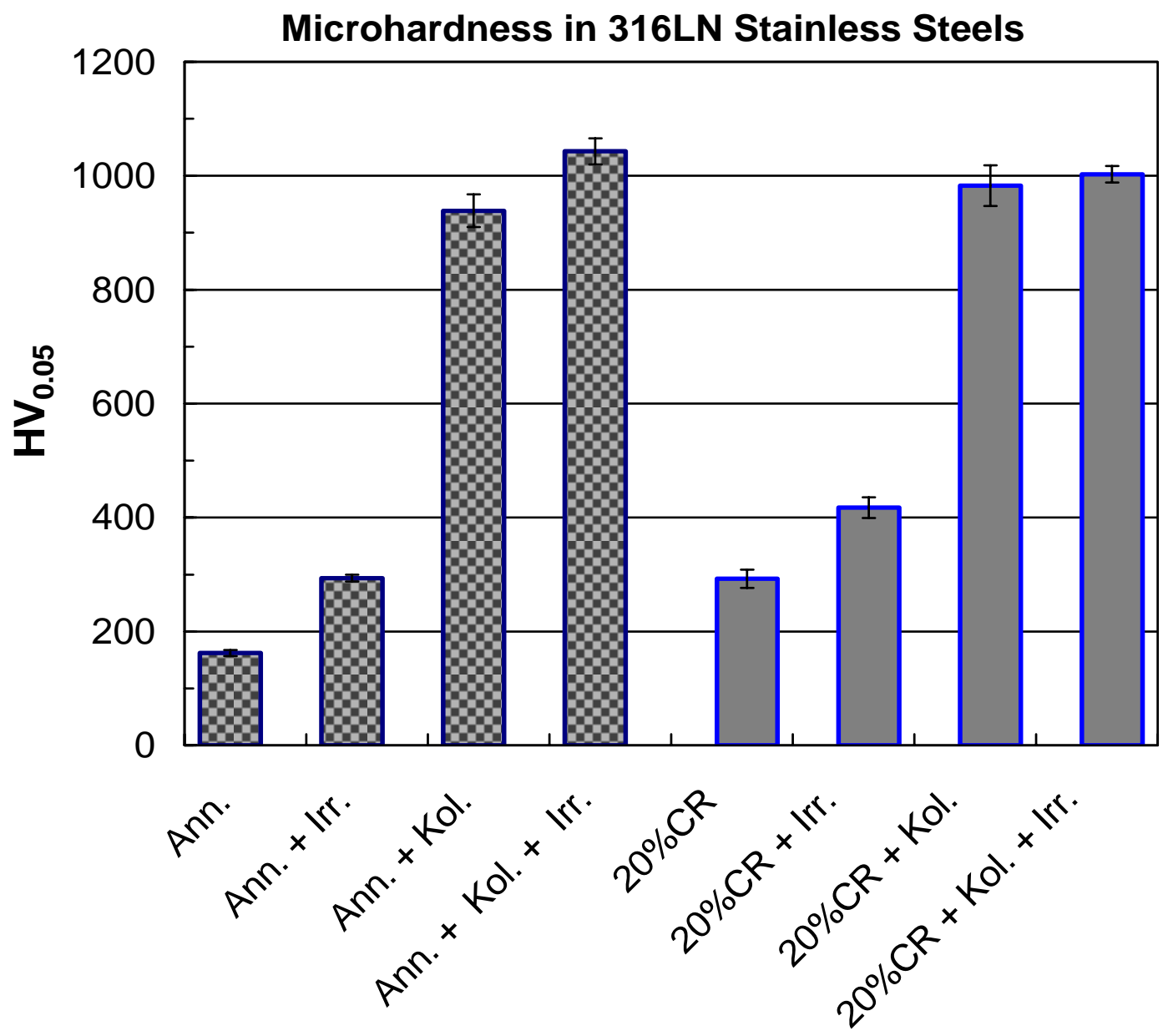

Fig. 1. Comparison of microhardness data for different material and surface conditions. 
Table 1. Microhardness data for annealed 316LN stainless steel disks

\begin{tabular}{|c|c|c|c|c|}
\hline $\begin{array}{l}\text { Material } \\
\text { condition }\end{array}$ & $\mathbf{H V}_{0.05}$ & Mean & $\begin{array}{c}\text { Standard } \\
\text { deviation }(\sigma)\end{array}$ & $\begin{array}{c}\Delta \mathrm{HV} \\
\text { (Irradiation } \\
\text { hardening) }\end{array}$ \\
\hline \multirow{6}{*}{ As-annealed } & 167 & \multirow{6}{*}{162} & \multirow{6}{*}{5} & \multirow{17}{*}{132} \\
\hline & 164 & & & \\
\hline & 162 & & & \\
\hline & 165 & & & \\
\hline & 162 & & & \\
\hline & 153 & & & \\
\hline \multirow{5}{*}{$\begin{array}{l}\text { Annealed + } \\
\text { irradiated }\end{array}$} & 288 & \multirow{5}{*}{294} & \multirow{5}{*}{6} & \\
\hline & 298 & & & \\
\hline & 299 & & & \\
\hline & 286 & & & \\
\hline & 298 & & & \\
\hline \multirow{6}{*}{$\begin{array}{l}\text { Annealed + } \\
\text { kolsterised }\end{array}$} & 965 & \multirow{6}{*}{939} & \multirow{6}{*}{29} & \\
\hline & 900 & & & \\
\hline & 946 & & & \\
\hline & 918 & & & \\
\hline & 927 & & & \\
\hline & 975 & & & \\
\hline \multirow{5}{*}{$\begin{array}{l}\text { Annealed + } \\
\text { kolsterised + } \\
\text { irradiated }\end{array}$} & 1017 & \multirow{5}{*}{1043} & \multirow{5}{*}{23} & \multirow{5}{*}{104} \\
\hline & 1072 & & & \\
\hline & 1027 & & & \\
\hline & 1061 & & & \\
\hline & 1038 & & & \\
\hline
\end{tabular}


Table 2. Microhardness data for $20 \%$ cold rolled $316 \mathrm{LN}$ stainless steel disks

\begin{tabular}{|c|c|c|c|c|}
\hline $\begin{array}{l}\text { Material } \\
\text { condition }\end{array}$ & $H V_{0.05}$ & Mean & $\begin{array}{c}\text { Standard } \\
\text { deviation }(\sigma)\end{array}$ & $\begin{array}{c}\Delta \mathrm{HV} \\
\text { (Irradiation } \\
\text { hardening) }\end{array}$ \\
\hline \multirow{6}{*}{$20 \%$ CR } & 281 & \multirow{6}{*}{293} & \multirow{6}{*}{16} & \multirow{17}{*}{125} \\
\hline & 312 & & & \\
\hline & 310 & & & \\
\hline & 280 & & & \\
\hline & 298 & & & \\
\hline & 275 & & & \\
\hline \multirow{5}{*}{$\begin{array}{l}20 \% \text { CR + } \\
\text { irradiated }\end{array}$} & 401 & \multirow{5}{*}{418} & \multirow{5}{*}{18} & \\
\hline & 438 & & & \\
\hline & 429 & & & \\
\hline & 396 & & & \\
\hline & 423 & & & \\
\hline \multirow{6}{*}{$\begin{array}{l}20 \% \text { CR + } \\
\text { kolsterised }\end{array}$} & 918 & \multirow{6}{*}{983} & \multirow{6}{*}{36} & \\
\hline & 985 & & & \\
\hline & 985 & & & \\
\hline & 1027 & & & \\
\hline & 996 & & & \\
\hline & 985 & & & \\
\hline \multirow{5}{*}{$\begin{array}{l}20 \% \text { CR + } \\
\text { kolsterised + } \\
\text { irradiated }\end{array}$} & 995 & \multirow{5}{*}{1003} & \multirow{5}{*}{14} & \multirow{5}{*}{20} \\
\hline & 1006 & & & \\
\hline & 1006 & & & \\
\hline & 1027 & & & \\
\hline & 996 & & & \\
\hline
\end{tabular}



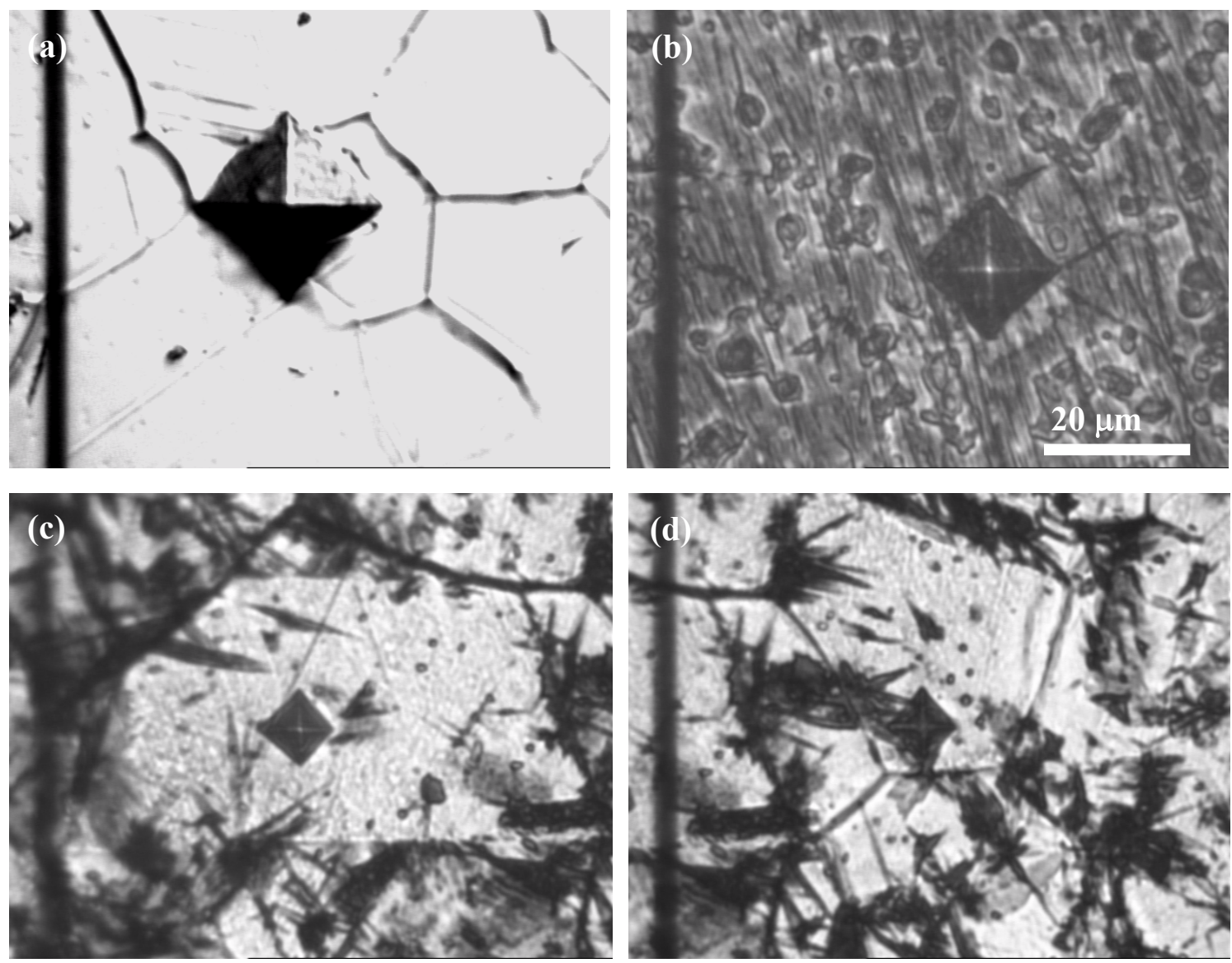

Fig. 2. Microstructures and indentation impressions in the annealed materials in (a) asannealed, (b) annealed + irradiated, (c) annealed + Kolsterised, and (d) annealed + Kolsterised + irradiated conditions. 

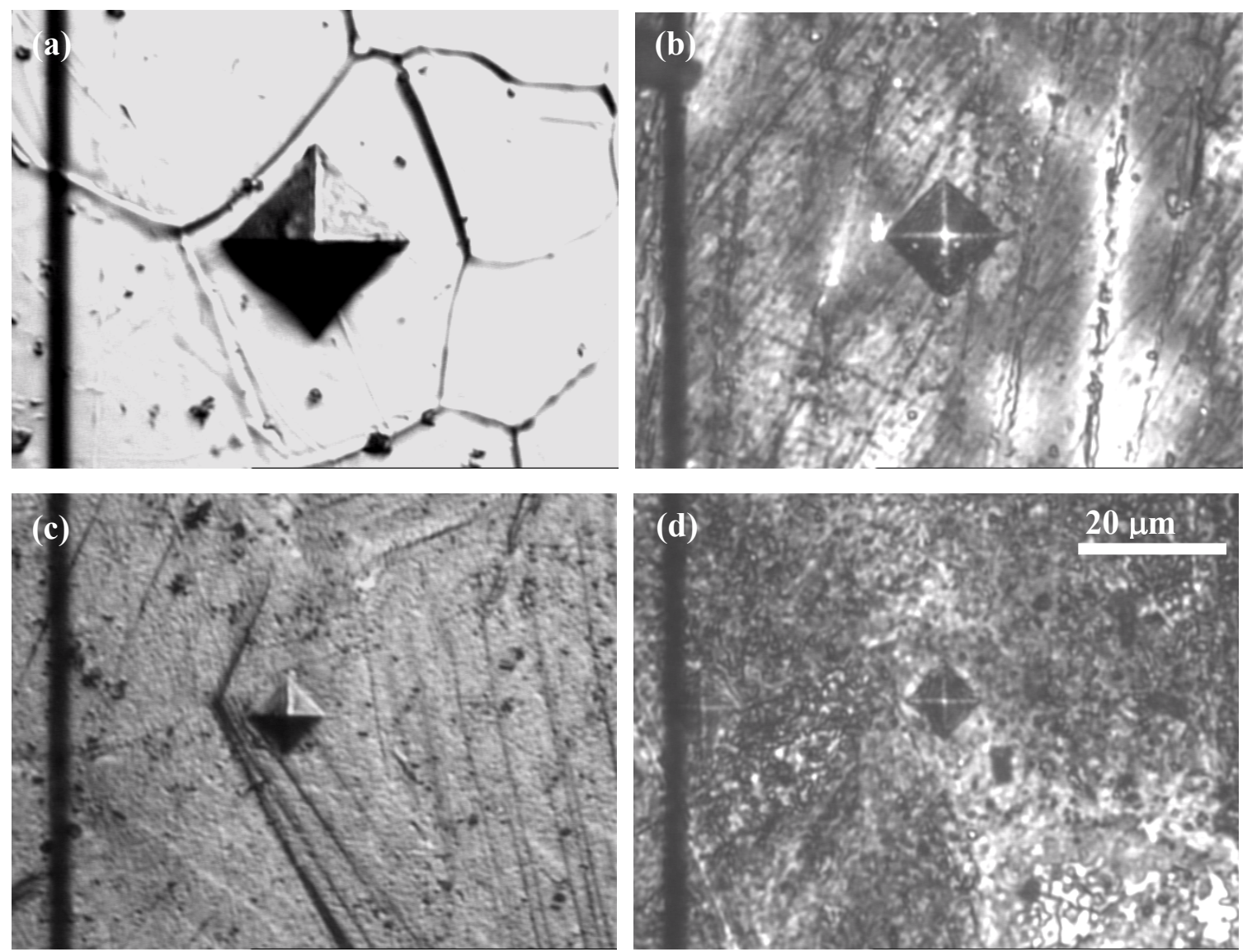

Fig. 3. Microstructures and indentation impressions in the $20 \%$ cold rolled materials in (a) asrolled, (b) rolled and irradiated, (c) rolled and Kolsterised, and (d) rolled, Kolsterised, and irradiated conditions. 


\section{INTERNAL DISTRIBUTION}

1. T. S. Byun

2. K. Farrell

3. J. R. Haines

4. L. K. Mansur

5. S. J. Pawel

6. S. J. Zinkle

\section{EXTERNAL DISTRIBUTION}

7. Günter Bauer, ILL

8. Masatoshi Futakawa, JAERI 